\title{
Growth performance, fatty acid profile and lipid oxidative stability of breast muscle in chickens fed probiotics and antibiotics or their mixture
}

\author{
N.R. Abdulla ${ }^{1,5}$, A.B. Sabow ${ }^{1,5}$, H.L. Foo ${ }^{3,4}$, T.C. Loh $^{1,2 \#}$ \& A.M. Zamri ${ }^{1}$ \\ ${ }^{1}$ Department of Animal Science, Faculty of Agriculture, Universiti Putra Malaysia, 43400 Serdang, Selangor, Malaysia. \\ ${ }^{2}$ Institute of Tropical Agriculture, Universiti Putra Malaysia, 43400 Serdang, Selangor, Malaysia \\ ${ }^{3}$ Department of Bioprocess Technology, Faculty of Biotechnology and Biomolecular Science, Universiti Putra Malaysia, \\ 43400 Serdang, Selangor, Malaysia \\ ${ }^{4}$ Institute of Bioscience, Universiti Putra Malaysia, 43400 Serdang, Selangor, Malaysia \\ ${ }^{5}$ Department of Animal Resource, Faculty of Agriculture, Salahaddin University-Erbil, Kurdistan Region, Iraq
}

(Received 4 May 2018; Accepted 15 August 2018; First published online 21 December 2018)

Copyright resides with the authors in terms of the Creative Commons Attribution 4.0 South African Licence.
See: http://creativecommons.org/licenses/by/4.0/za
Condition of use: The user may copy, distribute, transmit and adapt the work, but must recognise the authors and the South African Journal
of Animal Science.

\begin{abstract}
This study assessed the effects of dietary supplementation of probiotics, antibiotics and an antibioticprobiotics mixture on growth performance of broilers, and the fatty acid profile and oxidative stability of broiler breast muscle. A total of 480 one-day-old broiler chicks (Cobb 500) were assigned to four treatment groups and fed for 42 days. The basal diet served as control treatment (Diet 1), while chicks assigned to Diets 2, 3 and 4 were fed the basal diet with the addition of $0.1 \mathrm{mg} / \mathrm{kg}$ of an antibiotic growth promoter (AGP), a commercial probiotic $5 \mathrm{~g} / \mathrm{kg}$ or the AGP $(0.1 \mathrm{mg} / \mathrm{kg})+$ the commercial probiotic $(5 \mathrm{~g} / \mathrm{kg})$, respectively. Feed intake, weight gain and feed conversion ratio were determined. Fatty acid (FA) profile and lipid oxidative status were monitored at 1 and 7 days post mortem. The results showed no significant difference in average bodyweights among the treatments. However, birds fed Diets 3 and 4 had significantly lower feed conversion ratios and feed intake than the other treatments. At day 7 post mortem, the lipid oxidation in breast meat was significantly lower in Diet 3 compared with the other diets. The meat of the birds fed Diet 3 had lower oleic acid, but higher palmitic acid concentrations at 1 day post mortem. At 1 day postmortem the polyunsaturated fatty acid to saturated fatty acid (PUFA : SFA) ratio was significantly lower in the breast muscle of birds fed Diet 3 compared with those fed Diets 1 and 4 , but increased at 7 days postmortem. It could be concluded that probiotics supplementation showed high potential to improve oxidative stability, thereby increasing the shelf life of chicken meat.
\end{abstract}

Keywords: Bacillus subtilis, broiler, body weight, feed intake, lipid profile, storage stability

\#Corresponding author: tcloh@upm.edu.my

\section{Introduction}

In poultry production, the main objective is to obtain high productivity, combined with high product quality. For this, food additives are used, such as antibiotics with growth promoting properties (Roshanfekr \& Mamooee, 2009). However, the indiscriminate inclusion of antibiotics in animal feed since the early 1950s may have resulted in the development of antibiotics-resistant bacterial populations, leading to imbalances in the symbiosis between the animal and the desirable micro-biota in its digestive tract. A consequence is that some groups of consumers are avoiding the consumption of poultry meat of birds raised on diets containing antibiotics. It is therefore clear that there is a need for studies on alternative products that may replace antibiotics in animal feed without causing loss of productivity and lower quality of the end products. Probable growth-promoting replacements should maintain the beneficial actions of antibiotics, but eliminate undesirable side-effects, such as 
bacterial resistance. Such an alternative would be the use of probiotics, which are live microbial products that are beneficial to the host through an improved microbial equilibrium in the intestines (Abdulla et al., 2015). The most commonly used probiotic bacteria in poultry are Lactobacillus, Bifidobacterium, Bacillus, Streptococcus, Pediococcus and Enterococcus species (Manafi et al., 2018). The efficacy of probiotics in altering gut microbial balance, leading to enhanced feed utilization, growth performance and increased immunity, is well documented (Chichlowski et al., 2007; Taherpour et al., 2009). Recently, considerable attention has been devoted to the role of probiotics on lipid metabolism, implying that the fatty acid (FA) composition of poultry meat could be altered by probiotics (Park et al., 2016). Additionally, it has been suggested that the action of probiotics may be modulated by dietary polyunsaturated fatty acids (PUFAs), since they increase the colonization of certain bacteria strains in the small intestine (Marcinčák et al., 2009). Hascík et al. (2014) reported that dietary inclusion of probiotics increased monounsaturated fatty acid (MUFA) and PUFA concentrations of breast meat. Poultry meat is considered healthy owing to its relatively low fat content, which is a main source of PUFA compared with fat in the meat of other meat-producing animals (Dibner \& Buttin, 2002; Howe et al., 2006; Brenes \& Roura, 2010). However, a higher level of PUFAs in muscle membranes is associated with increasing susceptibility of meat and meat products to lipid oxidation (Adeyemi \& Olorunsanya, 2012a). PUFAs undergo rapid oxidative changes, which impair organoleptic characteristics and shortened shelf-life of meat (Lopez-Bote et al., 1998; Adeyemi \& Olorunsanya, 2012b). Furthermore, the susceptibility of poultry meat to lipid oxidation depends on the degree of unsaturation of the FAs, the presence of antioxidant and pro-oxidant substances in the meat and the nature of meat processing (Luna et al., 2010). Since probiotics have been implicated in the alteration of lipid metabolism, it is possible that susceptibility of muscle FAs to lipid oxidation could be influenced by probiotics supplementation. Additionally, another claim is that probiotics could have antioxidant properties (Bai et al., 2016). Various Bacillus species, including Bacillus subtilis have been used as additives for their positive effects of improving the antioxidant capacity in poultry production. Manafi et al. (2018) proved that spores of Bacillus subtilis are good candidates as a feed additive because this additive led to a reduction in protein and amino acid requirements for broiler chickens and, consequently, that the feed cost per kilogram weight gain could be reduced. However, the benefits of its use are not always observed unless they are associated with antibiotics. The efficacy of a probiotic is strictly dependent on the amount and characteristics of the strains of the microorganism used in the preparation of the food additive. Probiotics often do not produce good results, since microorganisms are included that do not meet the requirements to act as a probiotic, for example to survive in the adverse conditions of the gastrointestinal tract (action of bile and gastric, pancreatic and enteric juices), not to be toxic and pathogenic, to have the ability to antagonize bacterial intestinal diseases, be highly viable and stable during storage, and, in general, prove to be beneficial to the host. Some microorganisms that could act as probiotics do not resist the action of certain antibiotics and anti-coccidials that are used in poultry diets. It is therefore important that probiotics should be analysed as separate products in the same way as antibiotics. Additionally, the manufacturer of the probiotic, Gallipro, believes that a Bacillus subtilis strain has particular features, such as changing meat FA composition and resisting the reactive oxygen species including peroxide radicals, superoxide anions and hydroxyl radicals in meat. The authors could not establish if any investigations on this product had been carried out in chicken. Thus, the objective of this study was to determine the influence of the use of antibiotics, a probiotic containing Bacillus subtilis (GalliPro) and a combination of the antibiotic and probiotic in the diet of broilers on the growth performance (weight, weight gain, feed intake and feed conversion) and mortality of the birds, and the FA profile and lipid oxidation in their breast muscles.

\section{Materials and Methods}

The study was conducted according to the guidelines of research policy (AUP-R063/2016) of the Universiti Putra Malaysia on animal ethics.

A total of 480 one-day-old chicks (Cobb 500) were randomly divided into four treatment groups. The birds had free access to water and feed. The climatic conditions and lighting programme followed commercial recommendations. Environmental temperature in the first week of life was $32{ }^{\circ} \mathrm{C}$ and decreased to $25{ }^{\circ} \mathrm{C}$ until the end of the experiment. During the first week, 22 hours of light were provided, with a reduction to 20 hours afterwards.

Two basal diets, starter and grower-finisher were formulated. The starter diet was fed for the first three weeks, and the grower-finisher for the last three weeks of the experimental period. The composition of the basal 
diets is illustrated in Table 1. The dietary treatments were: Diet 1: basal diet (control); Diet 2: basal diet +0.1 $\mathrm{mg} / \mathrm{kg}$ of antibiotic growth promoter (AGP); Diet 3: basal diet $+5 \mathrm{~g} / \mathrm{k} \mathrm{g}$ of probiotic and Diet 4: basal diet +0.1

Table 1 Composition and nutrient content of starter and grower basal diets for broiler chickens (\%, as fed-basis)

\begin{tabular}{|c|c|c|}
\hline Ingredients (\%) & Starter & Finisher \\
\hline Corn & 50.6 & 55.0 \\
\hline Soybean ( $44 \%$ crude protein) & 29.4 & 26.9 \\
\hline Wheat Pollard & 6.1 & 6.4 \\
\hline Crude palm oil & 3.6 & 3.2 \\
\hline Fish meal (56\% crude protein) & 7.6 & 5.0 \\
\hline L-lysine & 0.25 & 0.25 \\
\hline DL-methionine & 0.2 & 0.2 \\
\hline Monodicalcium phosphate 21 & 1.0 & 1.4 \\
\hline Calcium carbonate & 0.68 & 0.99 \\
\hline Choline chloride & 0.060 & 0.058 \\
\hline Salt & 0.25 & 0.250 \\
\hline Mineral mix ${ }^{1}$ & 0.1 & 0.1 \\
\hline Vitamin $\mathrm{mix}^{2}$ & 0.06 & 0.06 \\
\hline Antioxidant (Butylated hydroxyanisole) & 0.01 & 0.08 \\
\hline Toxin binder (Hydrated odium calcium aluminum silicates) & 0.14 & 0.15 \\
\hline \multicolumn{3}{|l|}{ Calculated nutrient content } \\
\hline Crude protein (\%) & 22.5 & 20.3 \\
\hline Metabolizable energy $(\mathrm{Kcal} / \mathrm{kg})$ & 2919 & 2915 \\
\hline Lipid (\%) & 6.6 & 6.1 \\
\hline Fibre (\%) & 4.0 & 3.9 \\
\hline Calcium (\%) & 1.0 & 1.0 \\
\hline Total phosphorus (\%) & 0.80 & 0.81 \\
\hline Available phosphorus (\%) & 0.49 & 0.48 \\
\hline Salt (\%) & 0.42 & 0.37 \\
\hline Arginine (\%) & 1.46 & 1.32 \\
\hline Lysine (\%) & 1.44 & 1.28 \\
\hline Methionine + Cystine (\%) & 0.91 & 0.84 \\
\hline Methionine (\%) & 0.59 & 0.58 \\
\hline Threonine (\%) & 0.85 & 0.86 \\
\hline Tryptophan (\%) & 0.28 & 0.27 \\
\hline
\end{tabular}

\footnotetext{
${ }^{1}$ Multi mineral contained: Fe $100 \mathrm{mg}$, Mn $110 \mathrm{mg}$, Cu 20 mg, Zn $100 \mathrm{mg}$, I 2 mg, Se 0.2 mg, Co $0.6 \mathrm{mg}$.

${ }^{2}$ Multi vitamin contained: retinol $2 \mathrm{mg}$, cholecalciferol $0.03 \mathrm{mg}$, $\alpha$-tocopherol $0.02 \mathrm{mg}$, menadione $1.33 \mathrm{mg}$, cobalamin $0.03 \mathrm{mg}$, thiamine $0.83 \mathrm{mg}$, riboflavin $2 \mathrm{mg}$, folic acid $0.33 \mathrm{mg}$, biotin $0.03 \mathrm{mg}$, pantothenic acid $3.75 \mathrm{mg}$, niacin $23.3 \mathrm{mg}$, pyridoxine $1.33 \mathrm{mg}$.
}

$\mathrm{mg} / \mathrm{kg}$ of AGP $+5 \mathrm{~g} / \mathrm{kg}$ of probiotic. Diets were formulated to meet the requirements of all nutrients for broiler chickens. The antibiotic was a combination of oxytetracycline and neomycin at the concentration of $100 \mathrm{mg} / \mathrm{kg}$ (wt/wt) (Sunzen Berhad, Malaysia). The commercial probiotic source, GalliPro, contains an activity strain of Bacillus subtilis (DSM 17299) at a minimum concentration of $1.6 \times 10^{9}$ viable spores $/ \mathrm{g}$. All treatments were 
replicated six times. Each replicate (pen) consisted of 20 chicks and they were randomly assigned to an open house with wood shaving litter. Small amounts of antibiotic and probiotic were mixed in small quantities by adding them to ingredients such as L-lysine, DL-methionine, monodicalcium phosphate, calcium carbonate, choline chloride, salt, mineral mix, vitamin mix, antioxidant and toxin binder when the feed was prepared weekly.

Table 2 Fatty acid composition (\% of total identified fatty acids) of starter and grower diets for broiler chickens

\begin{tabular}{|c|c|c|}
\hline Fatty acids & Starter & Finisher \\
\hline Myristic acid (C14:0) & 0.547 & 0.445 \\
\hline Pentadecanoic acid (C15:0) & 0.262 & 0.256 \\
\hline Palmitic acid (C16:0) & 15.588 & 15.078 \\
\hline Palmitoleic acid (C16:1 n-7) & 0.591 & 0.611 \\
\hline Stearic acid (C18:0) & 3.330 & 3.175 \\
\hline Oleic acid (C18:1 n-9) & 22.759 & 23.088 \\
\hline Linoleic acid (C18:2 n-6) & 52.110 & 52.935 \\
\hline a-Linolenic acid (C18:3 n-3) & 4.275 & 4.004 \\
\hline Arachidonic acid (C20:4 n-6) & 0.127 & 0.101 \\
\hline Eicosapentaenoic acid C20:5 n-3 & 0.299 & 0.197 \\
\hline Docosahexaenoic acid (C22:6 n-3) & 0.111 & 0.109 \\
\hline $\mathrm{SFA}^{1}$ & 19.728 & 18.954 \\
\hline MUFA $^{2}$ & 23.349 & 23.699 \\
\hline PUFA $^{3}$ & 56.922 & 57.347 \\
\hline PUFA n-3 & 4.685 & 4.311 \\
\hline PUFA n-6 & 52.237 & 53.037 \\
\hline n6:n3 ratio & 11.149 & 12.303 \\
\hline PUFA:SFA & 19.728 & 18.954 \\
\hline
\end{tabular}

\footnotetext{
${ }^{1}$ SFA: sum of $\mathrm{C} 14: 0+\mathrm{C} 15: 0+\mathrm{C} 16: 0+\mathrm{C} 18: 0$

${ }^{2}$ MUFA: sum of C16:1+C18:1 n-9

${ }^{3}$ PUFA: sum of C18:2 n-6+C18:3 n-3+C20: $4 n-6+C 20: 5 n-3$

SFA: saturated fatty acid, MUFA: monounsaturated fatty acids, PUFA: polyunsaturated fatty acid,

PUFA n-3: omega-3 polyunsaturated fatty acids ratio, PUFA n-6: omega-6 polyunsaturated fatty acids, n6:n3 ratio: omega-3 polyunsaturated fatty acids : omega- 6 polyunsaturated fatty acids

PUFA:SFA: polyunsaturated fatty acid : saturated fatty acid
}

At the end of the experiment, 24 birds per treatment were randomly selected and weighed. The birds were slaughtered by neck decapitation, bled and processed. All measurements were assessed in breast muscles, which were removed at 45 min post mortem from the carcasses. All muscles were vacuum packaged and the samples for 1 and 7 days post mortem ageing were labelled and stored in a chiller $\left(4^{\circ} \mathrm{C}\right)$. At each ageing period, the appropriate packs were removed from the chiller and transferred to $-80{ }^{\circ} \mathrm{C}$ frozen storage until further analysis.

Lipid peroxidation in breast muscles was determined using the QuantiChrom ${ }^{\text {TM }}$ TBARS assay kit (DTBA100 Bioassay Systems, USA) following the procedure described by Sabow et al. (2016). TBARS measurements were determined on days 1 and 7 of post mortem ageing. 
The total FAs were extracted from breast muscles (approximately $1 \mathrm{~g}$ ) based on the method of Folch et al. (1957) modified by Rajion et al. (1985) using chloroform:methanol $2: 1(\mathrm{v} / \mathrm{v})$ containing butylated hydroxytoluene to prevent oxidation during sample preparation. The extracted FAs were transmethylated to their fatty acid methyl esters (FAME) using $0.66 \mathrm{~N} \mathrm{KOH}$ in methanol and $14 \%$ methanolic boron trifluoride $\left(\mathrm{BF}_{3}\right)$ (Sigma Chemical Co., St. Louis, MO, USA) according to the methods by AOAC (2000). FAME were separated by gas-liquid chromatography on an Agilent 7890A GC system (Agilent, Palo Alto, CA, USA) using a $100 \mathrm{~m} \times$ $0.25 \mathrm{~mm}$ ID $(0.20 \mu \mathrm{m}$ film thickness) Supelco SP-2560 capillary column (Supelco, Inc., Bellefonte, PA, USA). One microlitre of FAME was injected by an autosampler into the chromatograph, equipped with a flame ionization detector (FID). The carrier gas was He, and the split ratio was 10:1 after the injection of FAME. The injector temperature was programmed at $250{ }^{\circ} \mathrm{C}$, and the detector temperature at $300{ }^{\circ} \mathrm{C}$. The column temperature programme initially ran at $120^{\circ} \mathrm{C}$, held for $5 \mathrm{~min}$, increased by $2{ }^{\circ} \mathrm{C} / \mathrm{min}$ up to $170{ }^{\circ} \mathrm{C}$, held at $170{ }^{\circ} \mathrm{C}$ for $15 \mathrm{~min}$, increased again by $5^{\circ} \mathrm{C} / \mathrm{min}$ up to $200^{\circ} \mathrm{C}$, held at $200^{\circ} \mathrm{C}$ for $5 \mathrm{~min}$, then increased again by $2^{\circ} \mathrm{C} / \mathrm{min}$ to a final temperature of $235{ }^{\circ} \mathrm{C}$, and held for $10 \mathrm{~min}$. The fatty acid concentrations were expressed as percentage of total identified FA. A reference standard (mix C4-C24 methyl esters) Sigma-Aldrich, Inc., St. Louis, MO, USA) and CLA standard mix (CLA cis-9 trans-11 and CLA trans-10, cis-12) (Sigma-Aldrich, Inc., St. Louis, MO, USA) were used to determine recoveries and correction factors for the determination of individual FA composition.

The experiment followed a completely randomized design. Data obtained for intake and growth performance characteristics were analysed using the GLM procedure of Statistical Analysis System (SAS) package version 9.2 software (SAS, 2007), while the data obtained for FAs and lipid oxidation were subjected to a one-way repeated measure analysis. Significance was set at $P<0.05$ and differences between means were separated by least significant difference.

\section{Results and Discussion}

The feed intake and growth performance of birds fed various additives are shown in Table 3.

Table 3 Effect of antibiotics, probiotics and antibiotic-probiotic mixture on growth performance characteristics in broiler chickens

\begin{tabular}{lccccc}
\hline \multirow{2}{*}{ Parameter } & \multicolumn{4}{c}{ Dietary treatments } & \multirow{2}{*}{ SEM } \\
\cline { 2 - 4 } & Diet 1 & Diet 2 & Diet 3 & Diet 4 & \\
\hline Feed intake (kg) & $3.65^{\mathrm{a}}$ & $3.66^{\mathrm{a}}$ & $3.55^{\mathrm{b}}$ & $3.60^{\mathrm{a}}$ & 0.05 \\
Average daily gain (g) & 49.9 & 50.8 & 51.1 & 52.0 & 0.34 \\
Bodyweight (kg) & 2.13 & 2.17 & 2.18 & 2.22 & 0.01 \\
Total weight gain (kg) & 2.09 & 2.13 & 2.15 & 2.18 & 0.01 \\
Feed conversion ratio & $1.75^{\mathrm{a}}$ & $1.73^{\mathrm{ab}}$ & $1.66^{\mathrm{b}}$ & $1.65^{\mathrm{b}}$ & 0.02 \\
Mortality (\%) & 1.66 & 0.83 & 0.83 & 0.83 & 0.00 \\
\hline
\end{tabular}

Diet 1: basal diet (control); Diet 2: basal diet supplemented with $0.1 \mathrm{mg} / \mathrm{kg}$ of antibiotic growth promoter; Diet 3: basal diet supplemented with commercial probiotic, $5 \mathrm{~g} / \mathrm{kg}$; Diet 4: basal diet supplemented with antibiotic growth promoter $0.1 \mathrm{mg} / \mathrm{kg}+$ commercial probiotic, $5 \mathrm{~g} / \mathrm{kg}$

${ }_{\mathrm{a}, \mathrm{b}}$ Means with different superscript in the same row are significantly different $(P<0.05)$

SEM: pooled standard error of mean

Birds fed sole probiotics had a significantly lower $(P<0.05)$ feed intake compared with those fed other treatments. Although the feed intake was similar $(P<0.05)$ among birds fed antibiotic-probiotic mix, antibiotics and the control, the intake was lower in antibiotic-probiotic mix than birds fed the control and antibiotic diets. There was no significant difference $(P>0.05)$ in the average daily gain, final weight and total weight gain among the treatments. However, the feed conversion ratio differed significantly. Birds fed probiotics alone (Diet 3 ) and probiotic-antibiotic mix (Diet 4$)$ had lower $(P<0.05)$ feed conversion ratio than other treatments. Similarly, 
Zaghari et al. (2015) reported that Bacillus subtilis strain (GalliPro) supplementation reduced feed intake and improved feed conversion ratio with no effect on weight gain throughout the trial, indicating that the probiotic exerted some beneficial effect on broilers. The superiority of the feed conversion ratio observed in birds fed Diets 3 and 4 corroborates the findings of Khaksefidi \& Rahimi (2005), Biggs et al. (2007) and Taherpour et al. (2009), in which probiotic administration decreased feed conversion ratio in broilers. Nonetheless, the report of Chichlowski et al. (2007) and Mountzouris et al. (2007) was contrary to the present findings. The discrepancies between the earlier and present findings could be because of differences in breed of bird, sex, experimental conditions, and level of dietary additives. Mechanisms by which probiotics influenced growth performance are well established. Probiotics alters gut microbial balance reducing the population of pathogenic bacteria, which improves digestion, absorption and efficiency of feed utilization (Kalavathy et al., 2003; Kalavathy et al., 2006). Total mortality percentage was significant different $(P<0.05)$ among experimental groups. The mortality of broiler chickens fed probiotics and antibiotics, or their mixture was $0.83 \%$, while that of the control group broiler chickens was 1.66\% (Table 3). Alkhalf et al. (2010) noted similar findings. Antibiotics kill bacteria and bacteriostatic weaken them by inhibiting their proliferation and facilitating their phagocytosis by the immune system. Furthermore, probiotics may protect chickens against certain avian pathogens by colonization in the gastrointestinal tract, by activating immunocytes, and stimulating systemic immune responses, by promoting the endogenous host defence mechanisms and by modulating the mucosal immune system. Probiotics have also been reported to stimulate the production of natural antibodies and to reduce lung damage (Talebi et al., 2008). Thus, the mortality rate decreases because broiler chickens become more resistant.

Lipid deterioration in fatty foods is the main cause of reduced shelf life due to progressive oxidation and enzymatic hydrolysis of unsaturated FAs (Kolsarıcı et al., 2010; Adeyemi \& Olorunsanya, 2012b; Sabow et al., 2016). The thiobarbituric acid reactive substance (TBARS) values expressed as mg malondialdehyde (MDA)/kg meat for breast muscles during post mortem ageing periods of broiler chicken fed additives is shown in Table 4.

Table 4 Thiobarbituric acid reactive substance (TBARS) values expressed as mg malondialdehyde (MDA)/kg meat for breast muscles during post mortem ageing periods of broiler chicken receiving different dietary treatments

\begin{tabular}{|c|c|c|c|c|c|c|}
\hline \multirow{2}{*}{ Variable } & \multirow{2}{*}{$\begin{array}{l}\text { Aging periods } \\
\text { (Day) }\end{array}$} & \multicolumn{4}{|c|}{ Dietary treatments } & \multirow[b]{2}{*}{ SEM } \\
\hline & & Diet 1 & Diet 2 & Diet 3 & Diet 4 & \\
\hline \multirow{3}{*}{$\begin{array}{l}\text { Lipid oxidation } \\
\text { (mg MDA/kg meat) }\end{array}$} & 1 & $0.390^{\mathrm{a}}$ & $0.313^{\mathrm{a}}$ & $0.309^{\mathrm{a}}$ & $0.326^{\mathrm{a}}$ & 0.02 \\
\hline & 7 & $1.246^{\mathrm{a}}$ & $1.132^{\mathrm{ab}}$ & $1.002^{b}$ & $1.129^{\mathrm{ab}}$ & 0.31 \\
\hline & & * & * & * & * & \\
\hline
\end{tabular}

\footnotetext{
${ }^{a, b}$ Means within the same row with different superscripts are significantly different $(P<0.05)$

* Means within the same column are significantly different $(P<0.05)$

Diet 1: basal diet (control); Diet 2: basal diet supplemented with $0.1 \mathrm{mg} / \mathrm{kg}$ of antibiotic growth promoter; Diet 3: basal diet supplemented with commercial probiotic $5 \mathrm{~g} / \mathrm{kg}$; Diet 3: basal diet supplemented with antibiotic growth promoter $0.1 \mathrm{mg} / \mathrm{kg}+$ commercial probiotic $5 \mathrm{~g} / \mathrm{kg}$

SEM: pooled standard error of mean
}

No significant differences $(P>0.05)$ among dietary supplementation of antibiotic, probiotics and a combination of the two were recorded on MDA concentration in breast muscle of chickens at 1 days post mortem. Breast muscles from broilers fed sole probiotics (Diet 3$)$ had the lowest TBARS value $(P<0.05)$ compared with the control, but were not significantly different $(P>0.05)$ from the other additives at 7 days post mortem. Probiotics showed high potential to improve oxidative stability and to increase the shelf life of chicken meat. This may be attributed to the decrease in the concentrations of PUFAs in the birds supplemented with probiotics (Table 5), which reduced lipid peroxidation, thereby reducing the malondialdehyde level in the meat. In 
addition, because the PUFA/saturated fatty acid (SFA) ratio was much higher in breast meat of control samples after 24 hours post mortem, this could explain the increase in oxidation, since there was a relative increase in PUFA availability, thus promoting the greater formation of free radicals. This observation is in agreement with that of Shimokomakillal (2012), who showed that the addition of probiotics in the diet of broiler chickens significantly decreased the rate of lipid decomposition in breast muscles after 90 days of freezing at $-20{ }^{\circ} \mathrm{C}$, when compared with the control group without probiotics in the diet. Aksu et al. (2005) reported similar results in their study in which they use of $0.2 \%$ probiotic in the diet resulted in significantly lower TBARS in broiler fillets. Hossain et al. (2012) reported that diets containing probiotic bacteria supplements significantly lowered the TBARS value in breast and thigh meat after 5 and 7 days of refrigeration compared with a control. Kaya \& Aksu (2005) reported that the use of probiotic in a dry-fermented sausage manufacture improved the characteristics of quality in sausage and prevented the lipid oxidation of sliced sausages during storage. Probiotic Bacillus bacteria have also been shown a positive influence on prolonging meat shelf life of broiler chicks by decreasing the lipid peroxidation index (Park \& Kim, 2014). Probiotic supplementation was shown to modulate the dynamics of oxidants and antioxidants in the body. For example, probiotics based on Bacillus species showed good

Table 5 Fatty acid composition (\% of total identified fatty acids) of the breast muscle in chicken fed various additives

\begin{tabular}{|c|c|c|c|c|c|}
\hline \multirow{2}{*}{ Fatty acids } & \multicolumn{4}{|c|}{ Dietary treatments } & \multirow{2}{*}{ SEM } \\
\hline & Diet 1 & Diet 2 & Diet 3 & Diet 4 & \\
\hline Myristic acid (C14:0) & 6.21 & 6.40 & 6.01 & 6.01 & 0.77 \\
\hline Pentadecanoic acid (C15:0) & 0.64 & 0.69 & 0.72 & 0.63 & 0.11 \\
\hline Palmitic acid (C16:0) & $22.85^{\mathrm{b}}$ & $23.20^{\mathrm{a}, \mathrm{b}}$ & $24.80^{\mathrm{a}}$ & $23.13^{\mathrm{a}, \mathrm{b}}$ & 1.52 \\
\hline Palmitoleic acid (C16:1 n-7) & 5.53 & 5.15 & 5.88 & 5.03 & 0.80 \\
\hline Stearic acid (C18:0) & 6.24 & 6.42 & 6.95 & 6.62 & 0.48 \\
\hline Oleic acid (C18:1 n-9) & $32.08^{\mathrm{a}}$ & $32.10^{\mathrm{a}}$ & $30.74^{\mathrm{b}}$ & $32.36^{\mathrm{a}}$ & 1.80 \\
\hline Linoleic acid (C18:2 n-6) & 13.61 & 13.58 & 12.60 & 13.47 & 1.22 \\
\hline a-Linolenic acid (C18:3 n-3) & 0.60 & 0.62 & 0.57 & 0.56 & 0.06 \\
\hline Arachidonic acid (C20:4 n-6) & 10.54 & 10.13 & 9.90 & 10.20 & 1.19 \\
\hline Eicosapentaenoic acid C20:5 n-3 & 1.94 & 1.87 & 1.80 & 1.96 & 0.20 \\
\hline $\mathrm{SFA}^{1}$ & 35.74 & 36.57 & 37.49 & 36.40 & 1.66 \\
\hline MUFA $^{2}$ & 37.61 & 37.25 & 37.62 & 37.40 & 1.97 \\
\hline PUFA $^{3}$ & 26.69 & 26.21 & 24.88 & 26.20 & 1.88 \\
\hline PUFA n-3 & 2.54 & 2.49 & 2.39 & 2.52 & 0.20 \\
\hline PUFA n-6 & 24.15 & 23.72 & 22.50 & 23.76 & 1.79 \\
\hline n6:n3 ratio & 9.55 & 9.52 & 9.49 & 9.41 & 0.82 \\
\hline PUFA : SFA & $0.77^{\mathrm{a}}$ & $0.70^{\mathrm{ab}}$ & $0.67^{\mathrm{D}}$ & $0.71^{\mathrm{ab}}$ & 1.45 \\
\hline
\end{tabular}

Diet 1: basal diet (control); Diet 2: basal diet supplemented with $0.1 \mathrm{mg} / \mathrm{kg}$ AGP; Diet 3: basal diet supplemented with commercial probiotic $5 \mathrm{~g} / \mathrm{kg}$; Diet 3: basal diet supplemented with AGP $0.1 \mathrm{mg} / \mathrm{kg}+$ commercial probiotic $5 \mathrm{~g} / \mathrm{kg}$

${ }^{1}$ SFA: sum of $\mathrm{C} 14: 0+\mathrm{C} 15: 0+\mathrm{C} 16: 0+\mathrm{C} 18: 0$

${ }^{2}$ MUFA: sum of C16:1+C18:1 n-9

${ }^{3}$ PUFA5 sum of C18:2 n-6+C18:3 n-3+C20: $4 n-6+C 20: 5 n-3$

${ }_{x, y}^{a, b}$ Means within the same row for each parameter with different superscripts are significantly different $(P<0.05)$

${ }^{x, y}$ Means within the same column with different superscripts are significantly different $(P<0.05)$

SEM: pooled standard error of the mean

SFA: saturated fatty acid, MUFA: Monounsaturated fatty acids, PUFA: polyunsaturated fatty acid, PUFA n-3: omega-3 polyunsaturated fatty acids ratio, PUFA $n-6$ : omega- 6 polyunsaturated fatty acids, $n 6: n 3$ ratio: omega- 3 polyunsaturated fatty acids : omega-6 polyunsaturated fatty acids, PUFA : SFA polyunsaturated fatty acid : saturated fatty acid 
antioxidant effect by inhibiting lipid peroxidation (Wang et al., 2017). The TBARS values observed at 7 days postmortem were significantly $(P<0.05)$ higher than those fed 1 day post mortem in all treatments, but the increment was lower in the probiotic-supplemented group (Table 4).

The present findings are similar to those of Adeyemi \& Olorunsanya (2012a); Adeyemi et al. (2013) and Kiliç etal. (2013), who observed that TBARS values of raw chicken samples increased gradually during the storage period. Lipids are chemically unstable. Thus, they are vulnerable to oxidation, particularly during post mortem and storage. Lipid oxidation is involved in the deterioration of flavour, formation of rancid odours, discoloration and production of potentially toxic compounds which can affect consumers' health (Sabow et al., 2016). The threshold value of TBARS (5 mg MDA/kg) for detecting off-odours and off-taste was not reached in the current study.

Fatty acid composition of the chicken muscle fed different dietary supplementations of antibiotic, probiotics or combination is summarized in Table 5.

The major FA that was detected in the muscle and affected by the dietary treatment was oleic acid (C18:1n-9), which accounted for more than $32 \%$ of total FAs (Table 5). The concentrations of C18:1n-9 in the breast muscle of broilers fed probiotic (Diet 3) was significantly $(P<0.05)$ lower than that of the control group (Diet 1), antibiotic (Diet 2) and antibiotic-probiotic mix (Diet 4) treatments. This result is similar to that of Král (2013), who reported that broilers fed probiotics had lower levels of C18:1n-9 compared with the control but the differences were not significant. Kalavathy et al. (2006) suggested that the supplementation of Lactobacillus cultures was more effective in reducing oleic acid than the SFAs. The authors suggested that the supplementation of Lactobacillus cultures may reduce the synthesis or absorption of oleic acid. According to Bonos et al. (2010), the FA composition of the consumed feed and of the animal tissues can be modified as a result of the action of the gut microflora, because the gut microorganisms are able to hydrogenise unsaturated organic acids to more saturated ones, or even to desaturate some organic acids. A reduced level of oleic acid has also been observed in the livers of rats fed a mixture of probiotics (Fukushima et al., 1999). No significant differences $(P>0.05)$ were observed in any of the SFA in the breast muscle except palmitic acid (C16:0), which was significantly higher in the probiotic alone group than other treatments. However, there were no significant differences $(P>0.05)$ among other treatments for this FA. The mechanisms by which dietary probiotics regulate the palmitic acid content of breast meat are not fully understood. Currently, it is well recognized that the probiotics are live microorganisms and cause a positive effect on animal health through administering the digestive tract. It is well accepted that the inclusion of probiotics such as Bacillus species can increase the palmitic acid content in the pectoral meat of broilers through a positive effect on the intestinal flora (Endo \& Nakano, 1999). On the other hand, the main metabolic product of Bacillus species is butyric acid (Diomande et al., 2015) and this may have an important effect on the C16:0 generation process in the breast muscle of broilers. The increased concentration of C16:0 in this study was in agreement with the findings of Král (2013) in which significant increase in levels of C16:0 were found in breast muscle of broilers supplemented with probiotics. The main PUFAs noticed in breast muscles of broiler chickens were linoleic acid (C18:2n- 6), linolenic acid (C18:3n-3), arachidonic acid (C20:4n-6) and eicosapentaenoic acid (C20:5n-3). The mean concentrations of C18:2n-6 ranged from $10.05 \%$ to $14.28 \%$ while $\mathrm{C} 18: 3 \mathrm{n}-3$ ranged from $0.47 \%$ to $0.75 \%$ although neither showed significant differences $(P>0.05)$ among the treatments. The longer chain $n-3$ and $n-6$ FAs $(C 20: 5 n-3$, C20:4n-6) followed a similar response to C18:3n-3 and C18:2n-6 concentrations. Kalavathy et al. (2006) also showed that feeding broiler chickens with Lactobacillus cultures had no effect on the individual PUFA of the muscle when compared with the control. Conversely, the authors found significantly $(P<0.05)$ higher levels of arachidonic acid (C20:4n-6) in the livers of Lactobacillus culture supplemented broilers. Fukushima et al. (1999) suggested that the increased level of arachidonic acid was due to the $\Delta 6$-desaturase activity in the liver microsomes of the probiotic-fed animals. This effect has generally linked to the main metabolic product (butyric acid) of probiotic Bacillus bacteria, which is involved directly or indirectly in various mechanisms that regulate cellular differentiation, growth, permeability and delta-6 desaturase gene expression (Diomande et al., 2015). It is speculated that bacterial metabolic products such as butyric acid have an important effect on the digestion process and secretary volume of gut-brain peptide of the host, and these may affect n-3 PUFA absorption in the gastrointestinal tract. On the other hand, PUFA and their metabolite, eicosanoids, are biologically active substances and act as local hormones that control important processes in an organism, mainly in inflammation 
or immunity, and as messengers in the central nervous system (Makheja, 1992), and increase the colonization of broiler chicken intestine with bacteria (Ringo et al., 1998). At day 1, the ratio of omega 6 to omega 3 FAs of broiler breast was higher in broilers fed the control diet, though not significantly different from other treatments. The range of $n 6: n 3$ ratio of breast muscle observed in the present study was slightly lower than those observed in the findings of Sarker et al. (2009), where the ratio was found to be $10.4: 1$. No significant differences were observed in the concentrations of total SFA, MUFA and PUFA among the treatments (Table 4). The present observation corroborates the findings of Král (2013), who noted no significant difference in the concentration of SFA, MUFA and PUFA between the control and probiotic treatments. Additionally, Hossain et al. (2012) reported no changes in SFA and MUFA in broiler chickens fed probiotic bacteria when compared with the control group. Likewise, the results of the study of Kalavathy et al. (2006) indicated that Lactobacillus cultures had little potential to modify the FA composition. However, according to Furuse et al. (1992), the FA composition of the consumed feed and of the animal tissues can be modified as a result of the action of the gut microflora, because the gut microorganisms are able to hydrogenate unsaturated organic acids to more saturated ones. PUFA : SFA ratios were significantly $(P<0.05)$ lower in the breast muscles of chicks fed probiotic alone than the control and antibiotic-probiotic mix. This may be due to the lower concentration of C18:3n-3 and C20:4n-6, or an increase in the proportion of SFAs.

\section{Conclusion}

The results of the present study indicate that performance indices except feed intake of broiler chickens fed probiotic alone are comparable with those of broiler chickens fed probiotic associated with the antibiotic. Birds fed probiotics alone had a significantly lower feed intake compared with those fed other treatments. The concentrations of total SFA, UFAs and PUFAs were not affected by dietary supplementation of antibiotics, probiotics or their mixture. However, probiotic supplementation significantly increased and lowered the concentration of palmitic acid and oleic acid, respectively, in broiler breast muscle. The use of probiotics or their mixture with antibiotics in the diet resulted in significantly lower oxidative spoilage in broiler breast meat over a 7 days post mortem ageing. Therefore, it may be inferred that, probiotic supplement can be used to enhance broilers meat by better shelf life during storage without resulting in poor growth performance.

\section{Acknowledgements}

This project was supported by Long-Term Research Grant Scheme (LRGS) - Food Security entitled 'Enhancing the competitiveness and sustainability of the poultry industry for food security' from the Ministry of Higher Education, Malaysia.

\section{Authors' Contributions}

TCL and HLF contributed to the idea, design and execution of the study. TCL and AMZ assisted in all broiler chicken procedures for the experiment. NRA, ABS and AMZ performed the fatty acid profile and lipid oxidative stability. NRA and ABS were responsible for the statistical analysis. All authors contributed equally to the write-up of the final manuscript.

\section{Conflict of Interest Declaration}

The authors declare that they have no competing interests.

\section{References}

Abdulla N.R., Mohd Zamri, A.N., Sabow, A.B., Kareem, K.Y., Nurhazirah, S., Ling, F.H., Sazili, A.Q. \& Loh, T.C., 2015. Physico-chemical properties of breast muscle in broiler chickens fed probiotics, antibiotics or antibiotic-probiotic mix. J. Appl. Anim. Res. Doi:10.1080/09712119.2015.1124330.

Adeyemi, K. \& Olorunsanya, O., 2012a. Effect of tomato (Lycopersicon esculentum) powder on oxidative stability and sensory characteristics of broiler meat. Afr. J. Food Agric. Nutr. Dev. 12, 6794-6808.

Adeyemi, K. \& Olorunsanya, O., 2012b. Comparative analysis of phenolic composition and antioxidant effect of seed coat extracts of four cowpea (Vigna unguiculata) varieties on broiler meat. Iran. J. Appl. Anim. Sci. 2, 343-349.

Adeyemi, K., Olorunsanya, O. \& Abe, O., 2013. Effect of citrus seed extracts on oxidative stability of raw and cooked chicken meat. Iran. J. Appl. Anim. Sci. 3, 195-199.

Aksu, M. I., Karaoğlu, M., Esenbuğa, N., Kaya, M., Macit, M. \& Ockerman, H., 2005. Effect of a dietary probiotic on some quality characteristics of raw broiler drumsticks and breast meat. J. Muscle Foods 16, 306-317.

Alkhalf, A., Alhaj, M. \& Al-Homidan, I., 2010. Influence of probiotic supplementation on blood parameters and growth performance in broiler chickens. Saudi J. Biol. Sci. 17, 219-225.

AOAC, 2000. Official methods of analysis of AOAC International,(17th ed.) Gaithersburg, MD, USA, AOAC, USA.

Bai, K., Huang, Q., Zhang, J., He, J., Zhang, L. \& Wang, T., 2016. Supplemental effects of probiotic Bacillus subtilis fmbJ on growth performance, antioxidant capacity, and meat quality of broiler chickens. Poult. Sci. 96, 74-82. 
Biggs, P., Parsons, C. \& Fahey, G., 2007. The effects of several oligosaccharides on growth performance, nutrient digestibilities, and cecal microbial populations in young chicks. Poult. Sci. 86, 2327-2336.

Bonos, E., Christaki, E. \& Paneri, P., 2010. Performance and carcass characteristics of Japanese quail as affected by sex or mannan oligosaccharides and calcium propionate. S. Afr. J. Anim. Sci. 40, 173-184.

Brenes, A. \& Roura, E., 2010. Essential oils in poultry nutrition: Main effects and modes of action. Anim. Feed Sci. Technol. 158, 1-14.

Chichlowski, M., Croom, J., McBride, B., Daniel, L., Davis, G. \& Kaci, M., 2007. Direct-fed microbial primalc and Salinomycin modulate wholebody and intestinal oxygen consumption and intestinal mucosal cytokine production in the broiler chick. Poult. Sci. 86, 1100-1106.

Dibner, J., \& Buttin, P., 2002. Use of organic acids as a model to study the impact of gut microflora on nutrition and metabolism. J. Appl. Poult. Res. 11, 453-463.

Diomande, S.E., Guinebretière, M.H., Broussolle, V. \& Brillard, J., 2015. Role of fatty acids in Bacillus environmental adaptation. Front. Microb. 6, 813-833.

Endo, T. \& Nakano, M., 1999. Influence of a probiotic on productivity, meat components, lipid metabolism, caecal flora and metabolites, and raising environment in broiler production. Nihon. Chikusan. Gakkaiho. 70, 207-218.

Folch, J., Lees, M. \& Sloane-Stanley, G., 1957. A simple method for the isolation and purification of total lipids from animal tissues. J. Biol. Chem. 226, 497-509.

Fukushima, M., Yamada, A., Endo, T. \& Nakano, M., 1999. Effects of a mixture of organisms, Lactobacillus acidophilus or Streptococcus faecalis on 6-desaturase activity in the livers of rats fed a fat- and cholesterol-enriched diet. J. Nutr. 15, 373-378.

Furuse, M., Murai, A. \& Okumura, J., 1992. Gut microflora can modify fatty acid composition in liver and egg yolk lipids of laying Japanese quail (Coturnix coturnix japonica). Comparative biochemistry and physiology. Comparative Physiol. 103, 569-571.

Hascík, P., Elimam, I., Garlík, J., Bobko, M., Tkácová, J., Trembecká, L. \& Kacániová, M., 2014. Fatty acid content in broiler's ross 308 meat muscles after using bee pollen and probiotic as supplementary diet into their feed mixture. J. Microbiol. Biotech. Food Sci. 4, 67-69.

Hossain, M.E., Ko, S.Y., Kim, G.M., Firman, J.D. \& Yang, C.J., 2012. Evaluation of probiotic strains for development of fermented Alisma canaliculatum and their effects on broiler chickens. Poult. Sci. 12, 3121-3131.

Howe, P., Meyer, B., Record, S. \& Baghurst, K., 2006. Dietary intake of long-chain $\omega-3$ polyunsaturated fatty acids: Contribution of meat sources. J. Nutr. 22, 47-53.

Kalavathy, R., Abdullah, N., Jalaludin, S. \& Ho, Y., 2003. Effects of Lactobacillus cultures on growth performance, abdominal fat deposition, serum lipids and weight of organs of broiler chickens. Br. Poult. Sci. 44, 139-144.

Kalavathy, R., Abdullah, N., Jalaludin, S., Wong, M. \& Ho, Y.W., 2006. Effects of Lactobacillus feed supplementation on cholesterol, fat content and fatty acid composition of the liver, muscle and carcass of broiler chickens. Anim. Res. 55, 77-82.

Kaya, M. \& Aksu, M.I., 2005. Effect of modified atmosphere and vacuum packaging on some quality characteristics of sliced 'sucuk'produced using probiotics culture. J. Sci. Food Agric. 85, 2281-2288.

Khaksefidi, A. \& Rahimi, S., 2005. Effect of probiotic inclusion in the diet of broiler chickens on performance, feed efficiency and carcass quality. Asian-Australas. J. Anim. Sci. 18, 1153.

Kiliç, B., Şmşek, A., Claus, J. \& Atllgan, E., 2013. Effect on encapsulated phosphates on lipid oxidation in ground beef and poultry meat during storage. 59th International Congress of Meat Science and Technology, Izmir, Turkey.

Kolsarıcı, N., Candogan, K., Akoglu, I. \& Halkman, A., 2010. Effect of frozen storage on alterations in lipids of mechanically deboned chicken meats. GIDA Journal of Food, 403-410.

Král, M., 2013. Fatty acids composition of broiler chickens fed diets with probiotics and malic acid. J. Anim. Sci. Biotechnol. 46, 26-29.

Lopez-Bote, C., Gray, J., Gomaa, E. \& Flegal, C., 1998. Effect of dietary administration of oil extracts from rosemary and sage on lipid oxidation in broiler meat. Br. Poult. Sci. 39, 235-240.

Luna, A., Labaque, M., Zygadlo, J. \& Marin, R., 2010. Effects of thymol and carvacrol feed supplementation on lipid oxidation in broiler meat. Poult. Sci. 89, 66-370.

Makheja, A.N., 1992. Atherosclerosis: the eicosanoid connection. Mol. Cell. Biol. 111, 137-142.

Manafi, M., Hedayati, M. \& Mirzaie, S., 2018. Probiotic Bacillus species and Saccharomyces boulardii improve performance, gut histology and immunity in broiler chickens. S. Afr. J. Anim. Sci. 4, 379-389.

Marcinčák, S., Nemcová, R., Sokol, J., Popelka, P., Gancarčíková, S. \& Švedová, M., 2009. Impact of feeding of flaxseed and probiotics on meat quality and lipid oxidation process in pork during storage. Slov. Vet. Res. 46(1), 1-41.

Mountzouris, K., Tsirtsikos, P., Kalamara, E., Nitsch, S., Schatzmayr, G. \& Fegeros, K., 2007. Evaluation of the efficacy of a probiotic containing Lactobacillus, Bifidobacterium, Enterococcus, and Pediococcus strains in promoting broiler performance and modulating cecal microflora composition and metabolic activities. Poult. Sci. 86, 309-317. 
Park, J. \& Kim, I., 2014. Supplemental effect of probiotic Bacillus subtilis B2A on productivity, organ weight, intestinal Salmonella microflora, and breast meat quality of growing broiler chicks. Poult. Sci. 93, 2054-2059.

Park, Y., Hamidon, F., Rajangan, C., Soh, K., Gan, C., Lim, T., Abdullah, W. \& Liong, M., 2016. Application of probiotics for the production of safe and high-quality poultry meat. Korean J. Food Sci. An. 36, 567- 576.

Rajion, M., McLean, J. \& Cahill, R.N., 1985. Essential fatty acids in the fetal and newborn lamb. Aust. J. Biol. Sci. $38,33-40$.

Ringo, E., Bendiksen, H.R., Gausen, S.J., Sundsfjord, A., Olsen \& R.E., 1998. The effect of dietary fatty acids on lactic acid bacteria associated with the epithelial mucosa and from faecalia of Arctic char, Salvelinus alpinus (L.). J. Appl. Microbiol. 85, 855-864.

Roshanfekr, H. \& Mamooee, M., 2009. Effect of dietary antibiotic, probiotic and prebiotic as growth promoters, on growth performance, carcass characteristics and hematological indices of broiler chickens. Pak. J. Biol. Sci. 12, 52-57.

Sabow, A.B., Sazili, A.Q., Aghwan, Z.A., Zulkifli, I., Goh, Y.M., Ab Kadir, M.Z. A., Nakyinsige, K., Kaka, U. \& Adeyemi, K.D., 2016. Changes of microbial spoilage, lipid-protein oxidation and physicochemical properties during postmortem refrigerated storage of goat meat. Anim. Sci. J. 87, 816-826.

Sarker, S., Kim, G. \& Yang, C., 2009. Effect of green tea (Camellia sinensis) and mixed probiotics on meat oxidation, fatty acids profile and cholesterol in broilers. 55th International Congress of Meat Science and Technology (ICoMST) in Denmark, Copenhagen

SAS. 2007. User's Guide. 9.2 edition. SAS Inst. Inc, Cary, NC, USA.

Shimokomakillal, A.O.M., 2012. The effects of biotic additives on growth performance and meat qualities in broiler chickens. Int. J. Poult. Sci. 11, 599-604.

Taherpour, K., Moravej, H., Shivazad, M., Adibmoradi, M. \& Yakhchali, B., 2009. Effects of dietary probiotic, prebiotic and butyric acid glycerides on performance and serum composition in broiler chickens. Afr. J. Biotechnol. 8, $2329-2334$.

Talebi, A., Amirzadeh, B., Mokhtari, B. \& Gahri, H., 2008. Effects of a multi-strain probiotic (PrimaLac) on performance and antibody responses to Newcastle disease virus and infectious bursal disease virus vaccination in broiler chickens. Avian Pathol. 3, 509-512.

Wang, Y., Wu, Y., Wang, Y., Xu, H., Mei, X., Yu, D., Wang, Y. \& Li, W., 2017. Antioxidant properties of probiotic bacteria. Nutr. 9, 521.

Zaghari, M., Zahroojian, N., Riahi, M. \& Parhizkar, S., 2015. Effect of Bacillus subtilis spore (GalliPro®) nutrients equivalency value on broiler chicken performance. Ital. J. Anim. Sci. 14, 94-98. 